\title{
Metode Simple Additive Weighting Untuk Menentukan Tampilan Perangkat Lunak Berdasarkan Prinsip Usability
}

\author{
Affi Nizar ${ }^{1}$, Fitri Marisa ${ }^{2}$ \\ ${ }^{1}$ affinizar6@gmail.com, ${ }^{2}$ fitrimarisa@ widyagama.ac.id
}

Program Studi Teknik Informatika, Fakultas Teknik,Universitas Widyagama Malang

\begin{abstract}
Izzy Storage software is a warehousing service to manage warehouse in managing stock of goods owned by a customer. To provide the best service, a software must have a user interface that matches usability criteria, such as learnbility, eficiency, memorability, error, and satisfaction. Simple Additive Weighting (SAW) method is used to help select the recommended user interface and meet usability criteria. The final result is the best user interface recommendation process with 0.00829 result.
\end{abstract}

Intisari-Perangkat lunak Izzy Storage merupakan layanan jasa pergudangan untuk memanajemen gudang dalam mengelola stok barang yang dimiliki suatu pelanggan. Untuk memberikan pelayanan yang terbaik, sebuah perangkat lunak harus memiliki user interface yang sesuai dengan kriteria usability, diantaranya adalah learnbility, eficiency, memorability, error, dan satisfaction. Metode Simple Additive Weighting (SAW) digunakan untuk membantu pemilihan user interface yang direkomendasikan dan memenuhi kriteria usability. Hasil akhir yang didapatkan adalah proses perankingan rekomendasi user interface terbaik dengan hasil 0.00829.

KataKunci-Manajemen Gudang, Izzy Storage, metode Fuzzy MADM, metode SAW, Usability, User Interface.

\section{PENDAHULUAN}

Perangkat lunak Izzy Storage menyediakan layanan pengelolaan stok barang pada gudang yang dimiliki oleh suatu pelanggan, yaitu berupa pengelolaan stok barang masuk dan barang keluar. Untuk memberikan pelayanan yang terbaik, perangkat lunak Izzy Storage harus memiliki user interface yang memenuhi prinsip usability. Prinsip usability yang digunakan diantaranya adalah learnability, eficiency, memorability, error, dan satisfaction. Tujuannya adalah untuk memudahkan admin dalam menambahkan suatu data, memudahkan pelanggan dalam pengecekan suatu data maupun melakukan pencarian data dengan mudah, serta lebih mengurangi kebingungan ataupun kesalahan dalam menggunakan suatu perangkat lunak [1].
Berdasarkan permasalahan tersebut peneliti menerapkan metode Simple Additive Weighting (SAW) yang digunakan untuk membantu pemilihan user interface yang telah direkomendasikan dan memenuhi kriteria usability. Langkah awal yang dilakukan adalah dengan menetapkan bobot kriteria yang ditetapkan oleh perusahaan. Setelah bobot kriteria didapatkan langkah selanjutnya adalah proses normalisasi matriks yang hasilnya akan diproses berdasarkan urutan terkecil hingga terbesar [2]. Proses ini dinamakan dengan perankingan, dari proses perankingan hasil urutan terbesar merupakan user interface terbaik dan telah memenuhi kriteria usability [3]. Hal ini dibuktikan dengan perolehan hasil akhir 0.00829 atas nama Arief yang merupakan hasil rekomendasi user interface terbaik. Dengan penggunaan metode ini didapatkan ke akuratan hasil sebanyak $80 \%$ [4].

\section{KAJIAN PUSTAKA}

\section{A. User Interface}

Definisi User Interface (UI) secara terjemahan berarti "antar muka" adalah cara di mana seseorang mengontrol aplikasi perangkat lunak atau perangkat keras. Sebuah antar muka pengguna yang baik memberikan pengalaman userfriendly, yang memungkinkan pengguna untuk berinteraksi dengan perangkat lunak atau perangkat keras dengan cara alami dan intuitif. Hampir semua program perangkat lunak memiliki antarmuka pengguna grafis, atau GUI [5]. Ini berarti program ini mencakup kontrol grafis, dimana pengguna dapat memilih menggunakan mouse atau keyboard. User Interface sangat berkolerasi dengan desain interface, adapun pengertian desain interface sendiri merupakan suatu gambaran mengenai struktur program [6]. Desain interface atau tampilan dibuat untuk memudahkan programmer dalam menterjemahkan ke dalam bentuk bahasa pemrograman. Desain interface dibuat berdasarkan flowchart yang telah dibuat. Setiap bagian-bagian dari flowchart kemudian didesain interfacenya[7].

\section{B.Usability}

Usability adalah suatu ukuran, dimana pengguna dapat mengakses fungsionalitas dari sebuah sistem dengan efektif, 
efisien dan memuaskan dalam mencapai tujuan tertentu. Usability ditentukan oleh 5 komponen kualitas berikut:

1. Learnability, Seberapa mudah pengguna menyelesaikan tugas-tugas dasar saat pertama kali menggunakan desain tersebut.

2. Eficiency, Seberapa mudah pengguna menyelesaikan tugas dasar saat pertama kali menggunakan desain tersebut.

3. Memorability, Ketikapengguna dalam waktu tertentu tidak menggunakan desain tersebut, seberapa cepat mereka mendapatkan kembali kemampuan tersebut.

4. Error, Seberapa banyak error yang pengguna buat, seberapa berat error tersebut, dan seberapa cepat mereka dapat pulih dari error-error yang ada.

5. Satisfaction, Seberapa nyaman desain tersebut digunakan oleh pengguna.

\section{C.Flowchart}

Bagan alir (flowchart) adalah bagan yang menggambarkan urutan instruksi proses dan hubungan satu proses dengan proses lainnya menggunakan simbol-simbol tertentu. Bagan alir digunakan sebagai alat bantu komunikasi dan dokumentasi. Bagan alir sistem (system flowchart) merupakan bagan yang menunjukkan pekerjaan secara keseluruhan dari sistem. Bagan ini menjelaskan urut-urutan dari prosedurprosedur yang ada di dalam sistem dan menunjukkan apa saja yang dikerjakan pada sistem[8].

\section{D.Entity Relationship Diagram (ERD)}

ERD (Entity Relationship Diagram) adalah model konseptual yang mendeskripsikan hubungan antara penyimpanan dalam DFD. ERD digunakan untuk memodelkan struktur data dan hubungan antar data.

\section{E.Simple Additive Weighting (SAW)}

Salah satu metode penyelesaian masalah MADM adalahdengan menggunakan metode Simple Additive Weighting (SAW). Metode SAW sering juga dikenal istilah metode penjumlahan terbobot. Konsep dasar metode SAW adalah mencari penjumlahan terbobot dari rating kinerja pada setiap alternatif dari semua atribut [9].

Langkah-langkahdarimetode SAW adalah:

1. Menentukan kriteria-kriteria yang akan dijadikan acuan dalam pengambilan keputusan, yaitu $\mathrm{C}$.

2. Menentukan rating kecocokan setiap alternatif pada setiap kriteria.

3. Membuat matriks keputusan berdasarkan kriteria (C), kemudian melakukan normalisasi matriks berdasarkan persamaan yang disesuaikan dengan jenis atribut (atribut keuntungan atau pun atribut biaya) sehinggA diperoleh matriks ternormalisasi R.

4. Hasil akhir diperoleh dari proses perankinganya itu penjumlahan dari perkalian matriks ternormalisasi $\mathrm{R}$ dengan vektor bobot sehinggadiperoleh nilai terbesar yang dipilih sebagai alternatif terbaik (A) sebagai solusi.

\section{METODE PENELITIAN}

\section{A. Alur Penelitian (Flowchart)}

Berikut ini merupakan alur penelitian (Flowchart) pada Gambar 1yang akan digunakan dalam penelitian. Tahap pertama adalah pengumpulan data yang berupa rekomendasi user interface dari para pengembang perangkat lunak. Setelah data terkumpul tahapan berikutnya adalah menentukan kriteria dan bobot kriteria[10]. Selanjutnya kriteria dan bobot kriteria akan digunakan untuk perhitungan dengan metode simple additive weighting (SAW), hasil dari perhitungan kemudian di ranking untuk mendapatkan rekomendasi terbaik dari sistem.

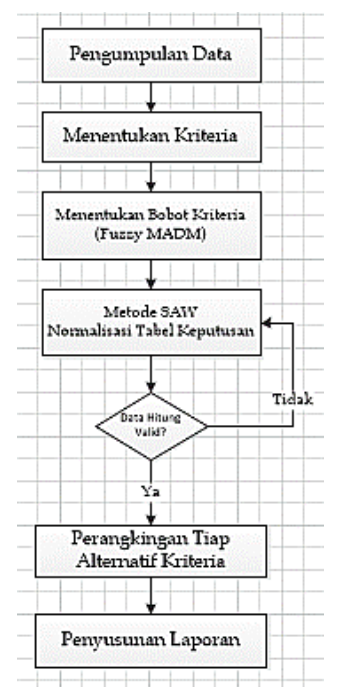

Gambar 1.Alur penelitian (flowchart)

\section{B.DFD (Data Flow Diagram)}

DFD adalah sebuah teknik grafis yang menggambarkan aliran informasi dan transformasi yang diaplikasikan pada saat data bergerak dari input menjadi output. Berikut ini adalah rancangan DFD level 0[11].

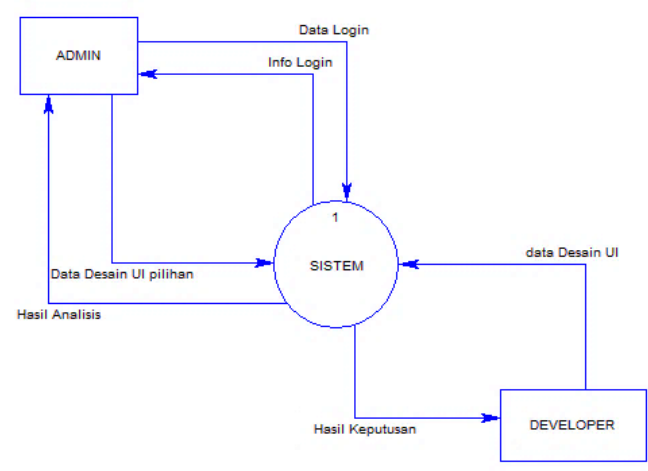

Gambar 2. Dfd level 0

Berdasarkan Gambar 2 dapat dijelaskan bahwa, Admin melakukan input data login berupa username dan password, dan melakukan input berupa data desain user interface yang 
sudah diseleksi. Kemudian developer melakukan input ke sistem berupa data desain user interface ke sistem. Admin akan menerima data info login oleh sistem dan hasil analisis desain user interface pilihan yang dilakukan oleh sistem. sementara developer akan menerima data hasil keputusan apakah desain user interface nya memenuhi syarat atau tidak. Setelah melalui proses dekomposisi maka diperoleh rancangan DFD level 1 pada Gambar 3.

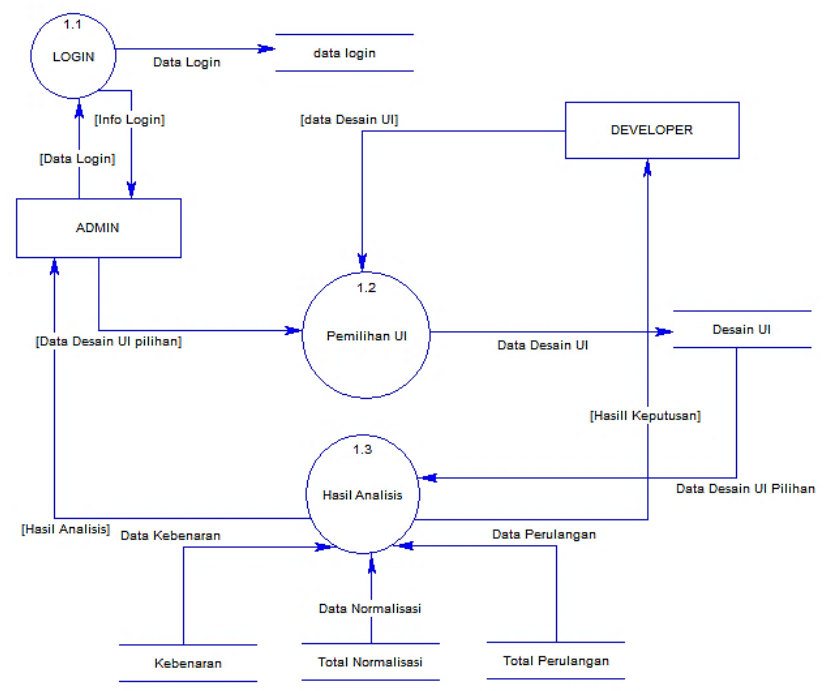

Gambar 3.Dfd level 1

Berdasarkan gambar 3 dapat dijelaskan bahwa terdapat 2 proses yang dilakukan yaitu, proses pemilihan user interface dan proses hasil analisis. Selain itu juga terdapat 5 storage yang akan digunakan yaitu, strorage data login, strorage desain user interface, storage total perulangan, storage total normalisasi, dan storage kebenaran.

\section{C.Rancangan Database}

Perancangan Database adalah proses merancang tabletable data yang terintegrasi dan berhubungan antara satu data dengan data yang lainya. Perancangan database akan digambarkan dengan Entity Relationship Diagram (ERD) pada Gambar 4.

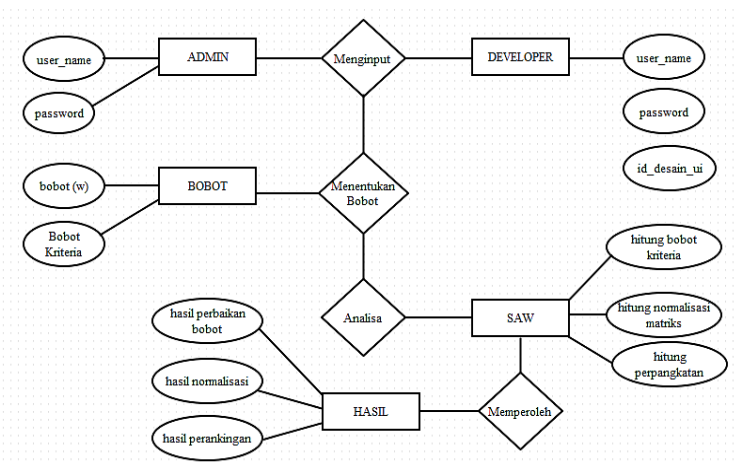

Gambar 4.ERD(Entity Relationship Diagram)
Berdasarkan Gambar 4 dapat dijelaskan bahwa terdapat lima tabel yang akan digunakan dalam rancangan database yaitu, tabel admin, tabel developer, tabel bobot, tabel SAW, dan tabel hasil.

\section{D.Analisis Kriteria Penilaian}

Kriteria yang akan dijadikan parameter terdiri dari 5 jenis, yaitu C1, C2, C3, C4, dan C5 yang dapat dilihat pada Tabel 1 berikut :

Tabel 1.

Kriteria usability

\begin{tabular}{|l|l|l|}
\hline Kode & Kriteria & Definisi \\
\hline C1 & Learnability & $\begin{array}{l}\text { Seberapa mudah pengguna } \\
\text { mempelajari }\end{array}$ \\
\hline C2 & Eficiency & $\begin{array}{l}\text { Seberapa cepat pengguna dalam } \\
\text { mengerjakan }\end{array}$ \\
\hline C3 & Memorability & $\begin{array}{l}\text { Seberapa inga tpengguna ketika } \\
\text { mengulang kembali }\end{array}$ \\
\hline C4 & Error & Seberapa banyak eror \\
\hline C5 & Satisfaction & $\begin{array}{l}\text { Seberapa nyaman desain tersebut } \\
\text { digunakan }\end{array}$ \\
\hline
\end{tabular}

Berdasarkan Tabel 1 itensitas kepentingan, maka diperoleh Tabel 3 bobot kriteria dan Tabel 2 bobot (W) sebagai berikut :

Tabel 2.

Tabel Bobot (W)

\begin{tabular}{|l|l|}
\hline \multicolumn{2}{|c|}{ TABEL BOBOT $(\mathbf{W})$} \\
\hline LEARNABILITY & 100 \\
\hline EFICIENCY & 80 \\
\hline MEMORABILITY & 70 \\
\hline ERROR & 90 \\
\hline SATISFACTION & 100 \\
\hline
\end{tabular}

Berdasarkan tabel bobot (w) diatas maka diperoleh tabel bobot kriteria yang besarnya sama dengan tabel bobot tetapi nilainya di ubah ke dalam bentuk desimal seperti tabel 3 berikut ini :

Tabel 3.

Bobot Kriteria

\begin{tabular}{|l|l|}
\hline \multicolumn{2}{|c|}{ TABEL BOBOT $(\mathbf{W})$} \\
\hline LEARNABILITY & 0,25 \\
\hline EFICIENCY & 0,2 \\
\hline MEMORABILITY & 0,2 \\
\hline ERROR & 0,2 \\
\hline SATISFACTION & 0,25 \\
\hline
\end{tabular}

Langkah selanjutnya adalah membuat tabel keputusan. Tabel keputusan ini diperoleh dari data desain user interface yang dikumpulkan oleh masing-masing developer, dari data yang telah terkumpul maka diperoleh nilai untuk masingmasing developer sesuai dengan kriteria usability yang telah ditentukan. Berikut ini adalah hasil tabel keputusan. 
Tabel 4.

Tabel Keputusan

\begin{tabular}{|l|l|l|l|l|l|}
\hline $\begin{array}{l}\text { DEVELO } \\
\text { PER }\end{array}$ & $\begin{array}{l}\text { LEARN } \\
\text { ABILITY }\end{array}$ & $\begin{array}{l}\text { EFICIE } \\
\text { NCY }\end{array}$ & $\begin{array}{l}\text { MEMORA } \\
\text { BILITY }\end{array}$ & $\begin{array}{l}\text { ERR } \\
\text { OR }\end{array}$ & $\begin{array}{l}\text { SATISF } \\
\text { ACTION }\end{array}$ \\
\hline DioIlham & 0,5 & 0,25 & 0,5 & 0,75 & 0,5 \\
\hline Arief & 0,75 & 0,5 & 0,75 & 1 & 0,75 \\
\hline Anam & 0,25 & 1 & 0,5 & 0,75 & 0,75 \\
\hline Shofrie & 0,75 & 0,5 & 0,25 & 0,75 & 0,75 \\
\hline Tony & 0,5 & 0,25 & 0,5 & 0,5 & 0,25 \\
\hline Novi & 0,25 & 0 & 0,75 & 0,5 & 0,5 \\
\hline
\end{tabular}

Berdasarkan Tabel 4 keputusan, maka dapat disimpulkan rentang nilai tertinggi hingga terendah yaitu, Nilai 0 (sangat rendah), Nilai 0,25 (Rendah), Nilai 0,5 (Sedang), Nilai 0,75 (Tinggi), Nilai 1 (Sangat Tinggi).

\section{HASIL DAN PEMBAHASAN}

\section{A. Hasil Matriks Normalisasi}

Setelah diperoleh Tabel 6 keputusan dan Tabel 3 bobot kriteria, maka langkah selanjutnya adalah melakukan normalisasi matriks dengan cara membagi nilai pada Tabel 4 keputusan dengan Tabel 2 bobot (w). Hasil Tabel 6 normalisasi matriks adalah sebagai berikut :

Tabel 6.

Hasil Normalisasi Matriks

\begin{tabular}{|l|l|l|l|l|l|}
\hline $\begin{array}{l}\text { DEVEL } \\
\text { OPER }\end{array}$ & $\begin{array}{l}\text { LEARNA } \\
\text { BILITY }\end{array}$ & $\begin{array}{l}\text { EFICI } \\
\text { ENCY }\end{array}$ & $\begin{array}{l}\text { MEMORA } \\
\text { BILITY }\end{array}$ & $\begin{array}{l}\text { ERRO } \\
\boldsymbol{R}\end{array}$ & $\begin{array}{l}\text { SATISF } \\
\text { ACTIO } \\
\boldsymbol{N}\end{array}$ \\
\hline Diollham & 0,005 & $\begin{array}{l}0,00312 \\
5\end{array}$ & $\begin{array}{l}0,00714285 \\
7\end{array}$ & $\begin{array}{l}0,00833 \\
3333\end{array}$ & 0,005 \\
\hline Arief & 0,0075 & 0,00625 & $\begin{array}{l}0,01071428 \\
6\end{array}$ & $\begin{array}{l}0,01111 \\
1111\end{array}$ & 0,0075 \\
\hline Anam & 0,0025 & 0,0125 & $\begin{array}{l}\mathbf{0}, 00714285 \\
7\end{array}$ & $\begin{array}{l}0,00833 \\
3333\end{array}$ & 0,0075 \\
\hline Shofrie & 0,0075 & 0,00625 & $\begin{array}{l}0,00357142 \\
9\end{array}$ & $\begin{array}{l}0,00833 \\
3333\end{array}$ & 0,0075 \\
\hline Tony & 0,005 & $\begin{array}{l}0,00312 \\
5\end{array}$ & $\begin{array}{l}0,00714285 \\
7\end{array}$ & $\begin{array}{l}0,00555 \\
5556\end{array}$ & 0,0025 \\
\hline Novi & 0,0025 & 0 & $\begin{array}{l}0,01071428 \\
6\end{array}$ & $\begin{array}{l}0,00555 \\
5556\end{array}$ & 0,005 \\
\hline
\end{tabular}

\section{B. Hasil Ranking}

Setelah diperoleh Tabel 6 hasil normalisasi matriks, tahap selanjutnya adalah menentukan Tabel 7 ranking yang merupakan hasil jumlah perkalian antara Tabel 6 hasil normalisasi matriks dengan Tabel 3bobot kriteria.

Tabel 7.

Hasil Ranking

\begin{tabular}{|l|l|}
\hline \multicolumn{2}{|c|}{ HASIL RANKING } \\
\hline DEVELOPER & HASIL \\
\hline DioIlham & 0,005505952 \\
\hline Arief & 0,008293651 \\
\hline Anam & 0,007380952 \\
\hline Shofrie & 0,00702381 \\
\hline Tony & 0,004325397 \\
\hline
\end{tabular}

Berdasarkan tabel perankingan diatas maka didapatkan nilai hasil dari sistem untuk masing-masing developer. Selanjutnya adalah menentukan developer mana yang desain user interfacenya layak untuk digunakan dan sesuai dengan kriteria usability yang diberikan. Langkah untuk menentukannya yaitu dengan mengurutkan hasil tertinggi hingga terendah dari tabel perankingan.

Maka desain user interface yang paling layak digunakan adalah desain user interface milik developer atas nama Arief (0.00829), desain tampilan user interface yang tidak memenuhi syarat usability adalah milik developer atas nama Novi (0.00405), desain user interface yang memenuhi beberapa persyaratan usability adalah milik developer atas nama Tony (0.00432) dan Dio Ilham (0.00550), sedangkan desain user interface yang dinilai hampir memenuhi persyaratan usability adalah milik developer atas nama Shofrie (0.00702) dan Anam (0.00738).

\section{KESIMPULAN DAN SARAN}

Berdasarkan penelitian yang dilakukan pada PT Aku Peduli Indonesia dapat ditarik kesimpulan. Pertama metode SAW lebih tepat untuk melakukan penilaian dan proses ranking pada kasus permasalahan pemilihan dengan jumlah kriteria yang banyak karena lebih efisien. Berdasarkan penelitian menggunakan metode SAW maka diperoleh desain user interface yang paling layak digunakan adalah desain user interface milik developer atas nama Arief (0.00829), desain tampilan user interface yang tidak memenuhi syarat usability adalah milik developer atas nama Novi (0.00405), desain user interface yang memenuhi beberapa persyaratan usability adalah milik developer atas nama Tony (0.00432) dan Dio Ilham (0.00550), sedangkan desain user interface yang dinilai hampir memenuhi persyaratan usability adalah milik developer atas nama Shofrie (0.00702) dan Anam (0.00738).

Berdasarkan hasil kesimpulan tentang analisis metode Simple Additive Weighting (SAW) untuk pemilihan desain user interface yang sesuai dengan prinsip Usability, maka PT Aku Peduli Indonesia harus lebih sering mengadakan sosialisasi kepada developer tentang pentingnya prinsip usability dalam pembuatan tampilan desain user interface yang baik. Sehingga para developer tidak akan bingung dan tidak menyimpang dari ketentuan yang seharusnya.

\section{DAFTAR PUSTAKA}

[1] A. Cahyapratama, "Application of Analytic Hierarchy Process ( AHP ) and Simple Additive Weighting ( SAW ) Methods In Singer Selection Process," no. Mcdm, pp. 234-239, 2018.

[2] J. W. Bell, "Simple Kalman filter alternative: the multi-fractional order estimator," no. April, pp. 827835, 2013.

[3] C. Science, "Cloud providers 'services evaluation using triangular fuzzy numbers," pp. 123-128, 2017.

[4] C. Study, U. Multimedia, and E. Siswanto, "Campus Promotion Management using Fuzzy Method," pp. 
75-80, 2017.

[5] M. Sam, “A Modified Algorithm for Full Fuzzy Transportation Problem with Simple Additive Weighting," pp. 684-688, 2018.

[6] A. Pranolo, "Simple Additive Weighting Method on Intelligent Agent for Urban Forest Health Monitoring," pp. 132-135, 2014.

[7] V. P. Muddineni, S. R. Sandepudi, S. M. Ieee, and A. K. Bonala, "Predictive Torque Control of Induction Motor Drive with Simplified Weighting Factor Selection," 2016.

[8] A. Mostafaeipour, "Implementing Data Envelopment Analysis ( DEA ) Methodology to Prioritize Wind Turbine Locations," 2015.

[9] J. Kittur, "Optimal Generation Evaluation using SAW , WP , AHP and PROMETHEE Multi - Criteria Decision Making Techniques ( mij ) K ( mij ) L,” pp. 304-309, 2015.

[10] F. N. Khasanah et al., "Fuzzy MADM for Major Selection at Senior High School," pp. 41-45, 2015.

[11] I. Irvanizam, "Multiple Attribute Decision Making with Simple Additive Weighting Approach for Selecting the Scholarship Recipients at Syiah Kuala University," no. ICELTICs, pp. 245-250, 2017. 
